\title{
Ingestion of 10 grams of whey protein prior to a single bout of resistance exercise does not augment Akt/mTOR pathway signaling compared to carbohydrate
}

Matthew B Cooke ${ }^{1,3}$, Paul La Bounty ${ }^{1}$, Thomas Buford ${ }^{1,4}$, Brian Shelmadine', Liz Redd ${ }^{1}$, Geoffrey Hudson ${ }^{1,5}$ and Darryn S Willoughby ${ }^{1,2^{*}}$

\begin{abstract}
Background: This study examined the effects of a whey protein supplement in conjunction with an acute bout of lower body resistance exercise, in recreationally-active males, on serum insulin and insulin like growth factor 1 (IGF-1) and Akt/mTOR signaling markers indicative of muscle protein synthesis: insulin receptor substrate 1 (IRS-1), AKT, mammalian target of rapamycin (mTOR), p70S6 kinase (p70S6K) and 4E-binding protein 1 (4E-BP1).

Methods: In a randomized, double-blind, cross-over design, 10 males ingested 1 week apart, either $10 \mathrm{~g}$ of whey protein (5.25 g EAAs) or carbohydrate (maltodextrose), 30 min prior to a lower-body resistance exercise bout. The resistance exercise bout consisted of 4 sets of 8-10 reps at 80\% of the one repetition maximum (RM) on the angled leg press and knee extension exercises. Blood and muscle samples were obtained prior to, and 30 min following supplement ingestion and 15 min and 120 min post-exercise. Serum and muscle data were analyzed using two-way ANOVA.

Results: No significant differences were observed for IGF-1 ( $p>0.05$ ). A significant main effect for Test was observed for serum insulin $(p<0.01)$ at 30 min post-ingestion and 15 and 120 min post-exercise, with no Supplement $\times$ Test interaction $(p>0.05)$. For the Akt/MTOR signaling intermediates, no significant Supplement $\times$ Test interactions were observed $(p>0.05)$. However, significant main effects for Test were observed for phosphorylated concentrations of IRS, mTOR, and p70S6K, as all were elevated at 15 min post-exercise $(p<0.05)$. Additionally, a significant main effect for Test was noted for 4E-BP1 $(p<0.05)$, as it was decreased at 15 min postexercise.

Conclusion: Ingestion of $10 \mathrm{~g}$ of whey protein prior to an acute bout of lower body resistance exercise had no significant preferential effect compared to carbohydrate on systemic and cellular signaling markers indicative of muscle protein synthesis in untrained individuals.
\end{abstract}

\section{Introduction}

The maintenance of skeletal muscle mass is determined by the long-term net balance of skeletal muscle protein synthesis (MPS) and muscle protein breakdown, defined by net protein balance. Though the balance between MPS and muscle protein breakdown is dependent upon feeding state [1-6] as well as training status $[7,8]$, changes in net

\footnotetext{
* Correspondence: darryn_willoughby@baylor.edu

'Department of Health, Human Performance and Recreation, Baylor University, Waco, TX, USA

Full list of author information is available at the end of the article
}

protein balance are thought to occur predominantly through changes in MPS, which is responsive to both resistance exercise and amino acid provision $[9,10]$. Resistance exercise leads to acute up-regulation of the inward amino acid transport [11] to the muscle resulting in an elevated fractional synthetic rate of muscle protein for as many as 48 hours following each exercise bout [12].

Some of the principle intracellular signaling pathways involved in MPS are becoming more defined in the literature [13]. As a result, determining the activity of the various pathways, specifically their intermediates, are often

\section{() Biomed Central}


used as markers of MPS. MPS is stimulated, at least in part, by the Akt/mTOR pathway, in which pathway intermediate activity is affected by the level of phosphorylation at different amino acid sites [14]. Specifically, the regulation of translation initiation via the Akt/mTOR pathway is recognized as a significant regulator of MPS [15]. Key downstream targets of the kinase mTOR include the eukaryotic initiation factor $4 \mathrm{E}$ (eIF4E) binding protein (4EBP1), which upon phosphorylation releases its inhibition over eIF4E to promote 5'-methylguanosine cap-dependent translation initiation and p70S6 kinase (p70S6K) [16]. Phosphorylation of $4 \mathrm{E}-\mathrm{BP} 1$ is important due to the fact that it prevents the interaction and inhibition of 4E-BP1 with eIF4E and hence, increases translation and MPS [16]. Conversely, p70S6K influences MPS partially through ribosomal protein S6 (rpS6) as well as through some other proteins such as eukaryotic elongation factor 2 (eEF2) [17].

Ingestion of supplementary protein (whole or as individual amino acids), either before or immediately following resistance exercise training, enhances Akt/mTOR pathway activity and MPS $[13,14]$. Notwithstanding, ingestion of protein or essential amino acids (EAA) with or without carbohydrate prior to, during, and in the early recovery phase following a bout of resistance exercise can lead to increased phosphorylation of mTOR [15,18], p70S6K [19-21], and rpS6 [22,23] within the first 4 hr post-exercise in both rodent and human models. These results also suggest that timing of ingestion is important, with increased circulation and nutrient transport to the skeletal muscle following exercise occurring concomitantly within the time period when MPS has the greatest elevation in response to exercise $[12,24,25]$. In addition, protein source and/or dosage appear to play a key role in pre- and postexercise muscle protein kinetics [26,27]. As little as $10 \mathrm{~g}$ of protein (4.2 g EAA) has been shown to stimulate MPS following resistance exercise [27], while acute ingestion of between 20-40 g of intact protein [28], or 9-10 g of EAA [25], seems to induce a plateau in MPS independent of exercise.

Albumin protein intake at a dose of $10 \mathrm{~g}$ (4.3 g EAAs) has been shown to significantly increase MPS, but had no effect on the activities of the Akt/mTOR pathway intermediates S6K1 $\left(\mathrm{Thr}^{389}\right)$, rps6 $\left(\mathrm{Ser}^{240 / 244}\right)$, or eIF2B $\varepsilon$ $\left(\mathrm{Ser}^{539}\right)$ after resistance exercise [10]. As a result, we sought to determine if $10 \mathrm{~g}$ of whey protein, but with 5.25 $\mathrm{g}$ of EAAs, would produce increases in other key Akt/ mTOR signalling intermediates following resistance exercise. Therefore, the primary purpose of this study was to determine the consumption of a whey protein supplement prior to an acute bout of lower body resistance exercise in recreationally active males on serum insulin and IGF-1 and the Akt/mTOR signaling markers indicative of MPS: IRS-1, AKT, mTOR, p70S6K and 4E-BP1.

\section{Methods}

\section{Participants}

Ten apparently healthy, recreationally-active (exercise 23 times per week), but not resistance-trained (no regular resistance training for at least one year) male participants $(20.1 \pm 1.4 \mathrm{yrs}, 174 \pm 8.7 \mathrm{~cm}, 78.5 \pm 12 \mathrm{~kg}$, ) participated in this study. All subjects signed informed consent documents and the study was approved by the Baylor University Institutional Review Board for the Protection of Human Subjects prior to any data collection. Subjects were not allowed to participate in this study if they reported any of the following: 1) current or past history of anabolic steroid use; 2) any metabolic disorders or taking any thyroid, hyperlipidmeic, hypoglycemic, antihypertensive, or androgenic medications; 3 ) ingested any ergogenic levels of creatine, $\mathrm{HMB}$, thermogenics, ribose, pro-hormones (i.e., DHEA, androstendione, etc.) or other purported anabolic or ergogenic nutritional supplements within 2 months prior to beginning the study; 4) not taking any additional nutritional supplement or contraindicated prescription medication during the protocol.

\section{Experimental design}

The study was conducted in a cross-over, randomized, double-blinded, and placebo-controlled manner. Participants expressing interest in the study were interviewed on the phone/or via email to determine whether they appear to qualify to participate in this study. Participants believed to meet eligibility criteria were then invited to attend an entry/familiarization session. Once reporting to the lab, participants completed a medical history questionnaire and underwent a general physical examination to determine whether they met eligibility criteria. Once cleared, participants were familiarized to the study protocol via a verbal and written explanation outlining the study design. All eligible participants who agreed to participate in the study read and signed the university-approved informed consent documents. Participants were familiarized with the angled leg press and leg extension machines, the correct technique in performing each of the exercises, and then performed two low-resistance (30\% of body mass) practice/warm-up sets of 10 repetitions on each exercise to familiarize them with the protocol and to also insure that they were able to complete the protocol before being formally admitted to the study. Participants then completed an initial strength test to assess their one repetition maximum (1-RM) for each leg on the angled leg press (Nebula Fitness, Inc., Versailles, $\mathrm{OH}$ ), and leg extension (Body Masters, Inc., Rayne, LA) exercises using standard guidelines routinely employed our laboratory [29]. Following the practice trials, participants were scheduled to return 48 hours later for testing. Participants were asked to not change their dietary habits in any way throughout 
the study. This was monitored by having each participant document dietary intake for two days before each testing session. In addition, each participant was instructed to fast for eight hours and not to perform any physical activity for the 48 hours proceeding each testing session.

\section{Resistance exercise protocol}

At the beginning of each testing session, participants had their body mass measured according to standard procedures using a self-calibrating digital scale (HealthO-Meter, Bridgeview, IL, USA) with an accuracy of \pm $0.02 \mathrm{~kg}$. Participants performed two separate bouts of resistance exercise, each session involving only one leg, each separated by two weeks. The supplement and leg utilized for the first exercise bout was randomly assigned. Using only one leg, participants performed 4 sets of 8-10 repetitions at 75\%-80\% 1-RM on the angled leg press (Nebula Fitness, Inc., Versailles, $\mathrm{OH}$ ) and knee extension (Body Masters, Inc., Rayne, LA) exercises. Each set was performed over the course of 25-30 seconds and followed by 120 seconds of rest, while 150 seconds of rest (1:5, work: rest ratio) were allowed between the two exercises. Training volume for each exercise was calculated by multiplying total number of reps by the total amount of weight lifted over the four sets.

\section{Supplementation protocol}

Participants were assigned in a double-blind and randomized manner to orally ingest 10 grams of maltodextrose placebo $(\mathrm{CHO})$ or whey protein (WP) containing $5.25 \mathrm{~g}$ of EAAs, mixed with $500 \mathrm{ml}$ of water. Supplements were ingested 30 minutes before each exercise session. Both supplements were isocaloric and independently prepared in individually blinded packages (Glanbia Nutritionals, Twin Falls, ID, USA). The amino acid composition of the WP supplement is displayed in Table 1.

\section{Dietary inventories}

For two days immediately prior to each testing session, participants were instructed to record all food and fluid intake, which was reflective of their normal dietary intake. Dietary inventories were then analyzed for average energy and macronutrient intake using the ESHA Food Processor Nutritional Analysis software (Salem, OR, USA).

\section{Blood and muscle collection procedures}

Approximately $20 \mathrm{ml}$ of venous blood was obtained from an antecubital vein using standard phlebotomy procedures on four separate occasions at each of the two resistance exercise sessions; 1) $30 \mathrm{~min}$ prior to exercise and ingestion of the supplement, 2) immediately before exercise following ingestion of the supplement, 3) 15 min post-exercise, and 4) 120 min post-exercise. Blood analyzed for serum IGF and insulin were placed into two serum separation
Table 1 Amino acid composition of the whey protein (WP) supplement $(\mathrm{g} / 500 \mathrm{ml})$

\begin{tabular}{ll}
\hline Essential Amino Acids (EAAs) & Concentration $\mathbf{( g )}$ \\
\hline Isoleucine & 0.61 \\
\hline Leucine & 1.55 \\
\hline Lysine & 0.76 \\
\hline Threonine & 0.85 \\
\hline Valine & 0.63 \\
\hline Methionine & 0.32 \\
\hline Tryptophan & 0.18 \\
\hline Phenylalanine & 0.35 \\
\hline Total EAAs & $\mathbf{5 . 2 5}$ \\
\hline Non-Essential Amino Acids (NEAAs) & Concentration (g) \\
\hline Aspartic Acid & 0.94 \\
\hline Serine & 0.45 \\
\hline Glutamic Acid & 1.47 \\
\hline Glycine & 0.14 \\
\hline Alanine & 0.59 \\
\hline Tyrosine & 0.27 \\
\hline Histidine & 0.16 \\
\hline Arginine & 0.14 \\
\hline Proline & 0.44 \\
\hline Cystine & 0.15 \\
\hline Total NEAAs & $\mathbf{4 . 7 5}$ \\
\hline Total Amino Acids & $\mathbf{1 0 . 0 0}$ \\
\hline
\end{tabular}

tubes and immediately centrifuged at $1,100 \mathrm{~g}$ for $15 \mathrm{~min}$. Serum was separated and stored at $-80^{\circ} \mathrm{C}$ in polypropylene cryovials for later analysis.

Approximately 50-75 mg of muscle was obtained from the lateral portion of the vastus lateralis midway between the patella and iliac crest of the leg using a 5-mm Bergstrom style biopsy needle. Muscle samples were taken on 3 separate occasions at each of the two resistance exercise sessions; 1) $30 \mathrm{~min}$ prior to exercise and ingestion of the supplement, 2) 15 min post-exercise, and 3) 120 min postexercise. Participants were instructed to refrain from exercise $48 \mathrm{hr}$ prior to each muscle biopsy. After removal, adipose tissue was trimmed from the muscle specimens and immediately frozen in liquid nitrogen and then stored at $-80^{\circ} \mathrm{C}$ for later analysis.

\section{Serum IGF and insulin}

The concentrations of serum insulin and IGF-1 were determined in duplicate and the average concentrations reported using commercially available enzyme-linked immunoabsorbent assay (ELISA) kits (Diagnostic Systems Laboratories, Webster, TX; Biosource, Camarillo, CA). Standard curves were generated using specific control peptides. Concentrations were determined at an optical density of $450 \mathrm{~nm}$ with a microplate reader (Wallac Victor 
1420, Perkin Elmer, Boston, MA, USA). The overall intraassay percent coefficient of variation was $4.6 \%$ and $2.9 \%$ for insulin and IGF-1, respectively.

\section{IRS-1 and Akt/mTOR signaling pathway protein expression}

Approximately $20 \mathrm{mg}$ of each muscle sample was homogenized using a commercial cell extraction buffer (Biosource, Camarillo, CA, USA) and a tissue homogenizer. The cell extraction buffer was supplemented with $1 \mathrm{mM}$ phenylmethanesulphonylfluoride (PMSF) and a protease inhibitor cocktail (Sigma Chemical Company, St. Louis, MO, USA) with broad specificity for the inhibition of serine, cysteine, and metallo-proteases. Muscle homogenates were analyzed for phosphorylated IRS-1 (Ser312), Akt (Ser473), 4E-BP1 (Thr46) and p70S6K (Thr389) using commercially-available phosphoELISA kits (Invitrogen, Carlsbad, CA, USA). This sensitivity of these particular assays is reported by the manufacturer to be less than $1 \mathrm{U} / \mathrm{mL}$. The absorbances, which are directly proportional to the concentration in the samples, were determined at $450 \mathrm{~nm}$ with a microplate reader (Wallac Victor 1420, Perkin Elmer, Boston MA, USA). A set of standards of known concentrations for each phosphorylated muscle variable were utilized to construct standard curves by plotting the net absorbance values of the standards against their respective protein concentrations. By applying a four part parameter curve using MikroWin microplate data reduction software (Microtek Lab Systems, Germany), the concentrations in the muscle samples were appropriately calculated. Protein concentrations were expressed relative to muscle wet-weight. The overall intra-assay percent coefficient of variation for all assays was less than 7\%

Phosphorylated mTOR was assessed through the use of ELISA used by methods previously described [29]. A polyclonal antibody specific for phosphorylated mTOR (Ser 2448), where target antigen specificities have been verified through Western blotting by the manufacturer, was purchased from Santa Cruz Biotech (Santa Cruz, CA). Initially, the antibody was diluted to $0.5 \mu \mathrm{g} / \mathrm{ml}$ in coating buffer ( $\mathrm{Na} 2 \mathrm{CO} 3, \mathrm{NaHCO} 3$, and ddH2O, pH 9.6) and allowed to incubate at room temperature overnight. Following incubation, the plates were washed $(1 \times$ phosphate buffered saline, Tween-20), blocked $(10 \times$ phosphate buffered saline, bovine serum albumin, ddH2O), washed, and then incubated with a secondary antibody (IgG conjugated to HRP) diluted to $0.5 \mu \mathrm{g} / \mathrm{ml}$ in dilution buffer $(10 \times$ phosphate buffered saline, Tween-20, bovine serum albumin, ddH2O). After washing, a stabilized TMB chromogen was added and the plates were covered and placed in the dark for the last 30-min prior to being stopped with $0.2 \mathrm{M}$ sulphuric acid. The subsequent absorbances, which are directly proportional to the concentration of the phosphorlyated mTOR in the samples, were measured at a wavelength of $450 \mathrm{~nm}$. There were no standards used in this ELISA, thus no standard curve was created. Therefore, the absorbances relative to muscle weight were assessed. The overall intra-assay percent coefficient of variation was $7.12 \%$.

\section{Statistical analyses}

Data are presented in all tables and throughout the text as mean \pm SD. Serum IGF and insulin were analyzed using $2 \times 4$ [Supplement $(\mathrm{CHO}, \mathrm{WP}) \times$ Test (pre, $30 \mathrm{~min}$ post supp, 15 min post-ex, and 120 min post-ex)] factorial analyses of variance (ANOVA) with repeated measures on the Test factor. Muscle protein levels were analyzed using $2 \times$ 3 [Supplement $(\mathrm{CHO}, \mathrm{WP}) \times$ Test (pre, 15 min post-ex, and 120 min post-ex)] factorial ANOVA with repeated measures on the Test factor. Further analysis of the main effects was performed by separate one-way ANOVAs. Significant between-group differences were determined using Bonferroni Post-Hoc Test. Participant characteristics, resistance exercise volume, and 1-RMs for the angled leg press and leg extension exercises for each testing session were analyzed using a paired sample t-test. All statistical procedures were performed using SPSS 16.0 software and a probability level of $\mathrm{p}<0.05$ was adopted throughout.

\section{Results}

\section{Participant characteristics and supplement side effects}

There were no significant differences in the body weight, resting blood pressure, or heart rate between the two testing sessions (data not shown). In a post-study questionnaire administered in a blinded manner, no adverse events were reported concerning the supplementation or study protocol.

\section{Dietary analysis}

Analysis of dietary intake (excluding supplementation) for two days immediately prior to each testing session revealed no differences $(\mathrm{p}>0.05)$ in total caloric, protein, fat, or carbohydrate intake between testing session during the course of the study (Table 2).

\section{Muscle strength and resistance exercise volume}

There were no significant differences in the 1-RM values between legs at each testing session for the angled leg press $(\mathrm{p}=0.35)$ and leg extension $(\mathrm{p}=0.42)$ exercises. The 1-RM for the leg press was $156.05 \pm 18.86 \mathrm{~kg}$ for the right leg and $154.29 \pm 25.52 \mathrm{~kg}$ for the left leg, and the 1$\mathrm{RM}$ for the leg extension was $44.94 \pm 3.91 \mathrm{~kg}$ for the right leg and $44.69 \pm 5.11 \mathrm{~kg}$ for the left leg. Additionally, there were no significant differences in the resistance exercise volume between the two testing sessions. The volume for leg press was $4744.5 \pm 960.4 \mathrm{~kg}$ for WP and 
Table 2 Dietary analyses performed two days immediately prior to each testing session

\begin{tabular}{lccc}
\hline Dietary Variable & WP & CHO & p-value \\
\hline Total Calories (kcal/kg/day) & $31.14 \pm 7.3$ & $30.43 \pm 5.1$ & 0.84 \\
\hline Protein (g/kg/day) & $0.83 \pm 0.2$ & $0.86 \pm 0.1$ & 0.73 \\
\hline Fat (g/kg/day) & $0.93 \pm 0.1$ & $0.96 \pm 0.1$ & 0.22 \\
\hline Carbohydrate (g/kg/day) & $4.40 \pm 0.9$ & $4.22 \pm 1.32$ & 0.13 \\
\hline
\end{tabular}

Data are means \pm standard deviations. SI unit conversion factor: $1 \mathrm{kcal}=4.2$ $\mathrm{kJ}$. Values exclude supplementation dose.

$4841.6 \pm 1212.9 \mathrm{~kg}$ for $\mathrm{CHO}(\mathrm{p}=0.89)$, and the volume for leg extension was $1187.5 \pm 267.6 \mathrm{~kg}$ for WP and $1285.2 \pm 180.1 \mathrm{~kg}$ for $\mathrm{CHO}(\mathrm{p}=0.35)$.

\section{Serum IGF-1 and insulin}

For IGF-1, no significant main effects for Supplement and Test or the Supplement $\times$ Test interaction were observed ( $\mathrm{p}>0.05$ ) (Table 3). For insulin, no significant main effect for Supplement or the Supplement $\times$ Test interaction was observed ( $\mathrm{p}>0.05$ ); although, a significant main effect for Test ( $p<0.001)$ was observed. Posthoc analysis showed significant differences between baseline, $30 \mathrm{~min}$ post-supplement ingestion, $15 \mathrm{~min}$ postexercise, and $120 \mathrm{~min}$ post-exercise (Table 3 ).

\section{Akt/mTOR signaling intermediates}

While no significant main effects for Supplement or the Supplement $\times$ Test interaction were observed for any of the variables $(\mathrm{p}>0.05)$, a significant main effect for Test $(\mathrm{p}<0.05)$ was observed for IRS-1 ( $=0.040)$, mTOR $(\mathrm{p}=0.002), \mathrm{p} 70 \mathrm{~S} 6 \mathrm{~K}(\mathrm{p}=0.046)$, and 4E-BP1 $(\mathrm{p}=0.001)$. No significant main effects for Test was observed for Akt $(\mathrm{p}=0.359)$. Subsequent analyses revealed a significant increase from baseline in IRS-1 at 15 and $120 \mathrm{~m}$ postexercise, an increase in mTOR and p70S6K at $15 \mathrm{~min}$ post-exercise, and a significant decrease in 4E-BP1 at 15 min post-exercise (Table 4).

\section{Discussion}

In the present study, we chose to assess changes in the activity of Akt/mTOR pathway intermediates as markers of MPS in response to resistance exercise after ingesting $10 \mathrm{~g}$ of whey protein. As a result, we observed resistance exercise to effectively activate signaling intermediates of the Akt/mTOR pathway. Specifically, we demonstrated increased phosphorylation of IRS-1, AKT, and mTOR. Relative to their downstream targets, p70S6K was hyperphosphorylated at 15 min post-exercise, whereas 4E-BP1 was hypo-phosphorylated at 15 min post-exercise. Conversely, we also observed that ingesting $10 \mathrm{~g}$ of whey protein was unable to induce a greater response in such kinase phosphorylation when compared to ingesting carbohydrate. Therefore, our results suggest that ingestion of $10 \mathrm{~g}$ of whey protein ( $5.25 \mathrm{~g}$ EAAs) is no different than an equal amount of carbohydrate at enhancing the activity of systemic and cellular signaling markers indicative of MPS following resistance exercise.

Resistance exercise and amino acids effectively stimulate MPS [30]. Based on previous studies, the role that nutrient ingestion plays in activating the Akt/mTOR pathway $[15,18-20]$ is not completely understood, and may likely be related to the amount of amino acids available or whether co-ingested with carbohydrate. Previous studies have demonstrated that $20 \mathrm{~g}$ of whey protein $(8.6$ g EAAs) [10] and $10 \mathrm{~g}$ EAAs [26] maximally stimulated MPS, but that MPS was also increased even at whey protein doses of $5 \mathrm{~g}$ (2.2 $\mathrm{g}$ EAAs) and $10 \mathrm{~g}$ (4.3 g EAAs) [10] and an EAA dose of $5 \mathrm{~g}$ [26]. When smaller amounts of EAAs (3-6 g) were ingested, with [31] and without [32] carbohydrate, the post-exercise increase in MPS was similar, but greater than basal or post-exercise fasted levels. In the present study, rather than assessing MPS, our interest was primarily focused on the extent with which $10 \mathrm{~g}$ of whey protein comprised of 5.25 EAAs would affect the activity of the Akt/mTOR pathway after resistance exercise when compared to carbohydrate alone

Table 3 Serum IGF-1 and insulin levels for WP and CHO

\begin{tabular}{|c|c|c|c|c|}
\hline Variable & Time Point & WP & $\mathrm{CHO}$ & $\mathrm{p}$-value \\
\hline \multirow[t]{4}{*}{ IGF-1 (ng/ml) } & Baseline & $0.46 \pm 0.4$ & $0.39 \pm 0.3$ & Supplement $(S)=0.64$ \\
\hline & 30 min post-ingestion & $0.47 \pm 0.4$ & $0.45 \pm 0.4$ & Test $(T)=0.34$ \\
\hline & 15 min post-exercise & $0.44 \pm 0.5$ & $0.39 \pm 0.3$ & $\mathrm{~S} \times \mathrm{T}=0.89$ \\
\hline & 120 min post-exercise & $0.50 \pm 0.4$ & $0.44 \pm 0.3$ & \\
\hline \multirow[t]{4}{*}{ Insulin ( $\mu|\cup / m|)$} & Baseline & $12.83 \pm 6.1$ & $14.05 \pm 7.1$ & Supplement $(S)=0.95$ \\
\hline & 30 min post-ingestion & $51.90 \pm 25.3$ & $50.59 \pm 34.9$ & Test $(T)=0.001+¥ \#$ \\
\hline & 15 min post-exercise & $23.60 \pm 14.1$ & $14.62 \pm 8.9$ & $S \times T=0.76$ \\
\hline & 120 min post-exercise & $10.08 \pm 6.5$ & $9.33 \pm 5.5$ & \\
\hline
\end{tabular}

Data are means \pm standard deviations.

$\dagger$ represents significant difference from baseline at $30 \mathrm{~min}$ post-ingestion.

$¥$ represents significant difference from baseline at $15 \mathrm{~min}$ post-exercise.

\# represents significant difference from baseline at $120 \mathrm{~min}$ post-exercise. 
Table 4 Phosphorylated levels of Akt/mTOR pathway intermediates for WP and CHO

\begin{tabular}{|c|c|c|c|c|}
\hline Variable & Time Point & WP & $\mathrm{CHO}$ & $p$-value \\
\hline \multirow[t]{3}{*}{ IRS-1 } & Baseline & $15.68 \pm 9.6$ & $19.52 \pm 6.4$ & Supplement $(S)=0.88$ \\
\hline & 15 min post-exercise & $29.04 \pm 6.6+$ & $22.28 \pm 11.2$ & Test $(T)=0.04 \dagger \#$ \\
\hline & 120 min post-exercise & $25.40 \pm 6.0$ & $19.65 \pm 9.2$ & $\mathrm{~S} \times \mathrm{T}=0.44$ \\
\hline \multirow[t]{3}{*}{ Akt } & Baseline & $5.04 \pm 1.9$ & $6.88 \pm 1.1$ & Supplement $(S)=0.21$ \\
\hline & 15 min post-exercise & $6.04 \pm 2.6$ & $5.61 \pm 4.1$ & Test $(T)=0.35$ \\
\hline & 120 min post-exercise & $4.78 \pm 1.4$ & $4.58 \pm 2.1$ & $\mathrm{~S} \times \mathrm{T}=0.82$ \\
\hline \multirow[t]{3}{*}{ mTOR } & Baseline & $3.34 \pm 0.34$ & $3.62 \pm 0.19$ & Supplement $(S)=0.93$ \\
\hline & 15 min post-exercise & $3.75 \pm 0.62$ & $3.66 \pm 0.27$ & Test $(T)=0.002 \dagger$ \\
\hline & 120 min post-exercise & $3.33 \pm 0.19$ & $3.52 \pm 0.28$ & $\mathrm{~S} \times \mathrm{T}=0.34$ \\
\hline \multirow[t]{3}{*}{ P70S6K } & Baseline & $8.51 \pm 3.2$ & $10.41 \pm 3.2$ & Supplement $(S)=0.96$ \\
\hline & 15 min post-exercise & $14.14 \pm 6.6$ & $11.18 \pm 2.9$ & Test $(T)=0.04$ \\
\hline & 120 min post-exercise & $13.32 \pm 6.1$ & $11.24 \pm 5.0$ & $\mathrm{~S} \times \mathrm{T}=0.74$ \\
\hline \multirow[t]{3}{*}{ 4E-BP1 } & Baseline & $4.30 \pm 2.4$ & $5.33 \pm 1.7$ & Supplement $(S)=0.28$ \\
\hline & 15 min post-exercise & $2.66 \pm 1.3 \dagger$ & $2.28 \pm 1.0$ & Test $(T)=0.001 \dagger$ \\
\hline & 120 min post-exercise & $4.07 \pm 1.9 \#$ & $4.90 \pm 1.8$ & $S \times T=0.64$ \\
\hline
\end{tabular}

Data are means \pm standard deviations.

p70S6K, elF4E-BP1, AKT and IRS-1 are expressed as $\mathrm{U} / \mathrm{ml} / \mathrm{mg}$.

$\mathrm{mTOR}$ is expressed as absorbance units at $450 \mathrm{~nm} / \mathrm{mg}$.

† represents significant difference from baseline at $15 \mathrm{~min}$ post-exercise.

\# represents significant difference from baseline at $120 \mathrm{~min}$ post-exercise.

and if this activity might also be systemically affected by either insulin or IGF-1. The reason for our interest was an attempt to discern if the $5.25 \mathrm{~g}$ of EAAs contained within $10 \mathrm{~g}$ of whey protein, without carbohydrate, was adequate to activate the Akt/mTOR compared to carbohydrate in response to a single bout of resistance exercise. Our interest was heightened by a previous study in which albumin protein intake at $10 \mathrm{~g}$ (4.3 g EAAs) significantly increased MPS, and maximally when $20 \mathrm{~g}(8.6 \mathrm{~g}$ EAAs) and $40 \mathrm{~g}$ (16.4 g EAAs) were ingested, yet none of the three concentrations had any affect on the activities of the Akt/mTOR pathway intermediates S6K1 $\left(\mathrm{Thr}^{389}\right)$, rps6 $\left(\mathrm{Ser}^{240 / 244}\right)$, or eIF2B $\varepsilon\left(\mathrm{Ser}^{539}\right)$ at 60 and $240 \mathrm{~min}$ post-exercise [10]. Despite previous evidence indicating otherwise [10], we were curious to determine if $10 \mathrm{~g}$ of whey protein would produce increases in other key Akt/ mTOR signalling intermediates following resistance exercise.

It is evident that acute resistance exercise results in a significant increase in the rate of initiation of protein synthesis compared with resting muscle [33]. It is suggested that signal transduction pathways control the rate of initiation of MPS, and appear to be the key factors in the hypertrophic process $[34,35]$. Of particular importance is the complex myriad of signaling proteins, with Akt suggested to be a key regulator. Maximal activation of Akt occurs through phosphorylation of Ser473 and it appears that Akt may have a relatively short period of activation after an acute bout of resistance exercise [36].
Research into the regulation of Akt signalling by exercise has produced conflicting results. A series of studies have demonstrated that contractile activity either positively or negatively regulates Akt activity [15,37-39], while others failed to find any change [40-42]. In the current study, we found that resistance exercise and nutrient ingestion failed to induce a significant change in the phosphorylation of Akt.

Stimuli of the Akt pathway includes hormones and muscle contraction. Insulin [43] and IGF-I [44] bind to their respective membrane-bound receptors and subsequently activate phosphatidylinositol-3 kinase (PI-3K), an upstream activator for Akt phosphorylation. Quantification of circulating IGF-I levels has yielded inconsistent results, with levels being reported to decline [45], increase [46], or remain unchanged [47] after the onset of exercise. Furthermore, circulating IGF-1 has been shown to have no direct effect on muscle hypertrophy [48]. In the current study, we observed no changes in serum IGF-1 following the exercise bout or due to nutrient ingestion, thereby suggesting hepatically-derived IGF-1 to have no appreciable effect on Akt pathway activation.

Serum insulin was increased in both groups. It is evident as to why insulin increased in the $\mathrm{CHO}$ group as $10 \mathrm{~g}$ of carbohydrate were ingested. In addition, the WP group also underwent a similar increase in insulin in the absence of ingested carbohydrate, which is in agreement with the insulin response previously demonstrated with $20 \mathrm{~g}$ of whey protein (10 g EAAs) [49]. The Akt/mTOR 
signalling pathway is activated by insulin. Insulin binds with its receptor and leads to an increase in tyrosine phosphorylation of IRS-1 and eventually mTOR activation. In the present study, insulin significantly increased in both groups 30 min post-supplement ingestion and 15 min post-exercise, which was mirrored by significant increases in IRS- 1 activation at 15 min post-exercise. Even though Akt phosphorylation was not significantly increased, activation of IRS-1 likely contributed to the observed increases in mTOR activation; however, this activity was not preferentially contingent on $10 \mathrm{~g}$ of whey protein ingestion.

mTOR is a $289 \mathrm{kDa}$ serine/threonine kinase downstream of Akt and stimulates protein synthesis through downstream activation of p70S6K and 4E-BP1, providing a key point of convergence for both resistance exercise and amino acids [14]. Amino acid ingestion has been shown to significantly enhance mTOR signalling $[25,50]$. In the present study, the acute bouts of resistance exercise significantly increased mTOR and p70S6K activation at $15 \mathrm{~min}$ post-exercise, while a marked decrease in 4E-BP1 activation was also observed at 15 min post-exercise. While we observed mTOR activation to be enhanced by resistance exercise, the Akt/mTOR pathway signalling intermediates we assessed were unaffected by the provision of $10 \mathrm{~g}$ of whey protein comprised of $5.25 \mathrm{~g}$ EAAs.

Previous work has suggested that a minimal amount of $20 \mathrm{~g}$ is needed to stimulate MPS [10]; however, others have demonstrated positive effects utilizing a dosage as low as $6 \mathrm{~g}$ EAAs [51]. Increases in MPS following resistance exercise have been observed when utilizing $10 \mathrm{~g}$ of whey protein; however, the protein supplement was co-ingested with $21 \mathrm{~g}$ of carbohydrate [26]. However, it has recently been shown that approximately $5 \mathrm{~g}$ (2.2 g EAAs) and $10 \mathrm{~g}$ (4.2 g EAAs) of whey protein without carbohydrate significantly increased MPS $37 \%$ and $56 \%$, respectively, over baseline. In this study, it was also shown that $20 \mathrm{~g}$ ( $8.6 \mathrm{~g}$ EAAs) maximally stimulated MPS following resistance exercise [27]. Although, our results are supported by previous data which demonstrated that $20 \mathrm{~g}$ of albumin protein $(8.6 \mathrm{~g}$ EAAs) enhanced MPS after resistance exercise, yet had no effects on activation of the mTOR pathway intermediates, S6K1, rps6, and eIF2B $\varepsilon$ post-exercise [27], the dosage used in the current study ( $10 \mathrm{~g}$ whey protein, $5.25 \mathrm{~g}$ EAA) was apparently insufficient to reach an amino acid dosage capable of stimulating Akt/mTOR pathway activity.

A number of limitations exist in the current study. Firstly, we only assessed the relative changes in the phosphorlated levels of various Akt/mTOR pathway intermediates. Thus, these can only be used as markers indicative of MPS. We did not measure protein synthesis directly and thus caution needs to be taken when interpreting changes in phosphorylation status of signaling pathway intermedi- ates to imply changes in human MPS, as this does not always determine functional changes. Secondly, no control was used and thus no direct comparison between isoenergetic carbohydrate and whey protein and resistance exercise could be made. However, previous research has clearly indicated that resistance exercise robustly activates Akt/mTOR signalling. Thirdly, only one dosage was used (10 g) and thus any comparison between other dosages cannot be made directly. Finally, our study focused on the early post-exercise recovery response in signalling and, therefore, we acknowledge the possibility that long-term activation of Akt/mTOR signalling and its downstream targets such as at 6,24 , or $48 \mathrm{hr}$ post-exercise may be better indicators of muscle MPS over the course of a resistance training program.

In conclusion, the present study shows that ingestion of $10 \mathrm{~g}$ whey protein (5.25 g EAAs) prior to a single bout of lower body resistance exercise had no significant effect on activating systemic and cellular signaling intermediates of the Akt/mTOR pathway, otherwise indicative of MPS, in untrained men. Future research should examine the effects of dose response and timing of protein ingestion and compare the effects of various forms/fractions of proteins on post-exercise cell signalling responses to resistance exercise.

\section{Acknowledgements}

The authors would like to thank the study participants for their hard work and willingness to donate blood and muscle biopsy samples. This work was supported by Glanbia Nutritionals, Twin Falls, ID, USA and the Exercise and Biochemical Nutrition Laboratory at Baylor University.

\section{Author details}

'Department of Health, Human Performance and Recreation, Baylor University, Waco, TX, USA. ${ }^{2}$ Institute for Biomedical Studies, Baylor University, Waco, TX, USA. ${ }^{3}$ Schools of Medicine and Human Movement Studies, The University of Queensland, Brisbane, QLD, Australia. ${ }^{4}$ Department of Aging and Geriatric Research, University of Florida, Gainesville, FL, USA. ${ }^{5}$ School of Human Performance and Recreation, University of Southern Mississippi, Hattiesburg.

\section{Authors' contributions}

MC coordinated the study, carried out the exercise sessions and all analyses, and drafted the manuscript. PLB carried out the exercise sessions and helped with analysis. TB helped with the biochemical analysis LR helped with exercise testing sessions BS helped with exercise sessions biochemical analysis GH helped with exercise sessions biochemical analysis. DSW conceived the study, developed the study design, secured the funding for the project, assisted and provided oversight for all data acquisition and statistical analysis, assisted and provided oversight in drafting the manuscript, and served as the faculty mentor and principal investigator for the project. All authors read and approved the final manuscript.

\section{Competing interests}

All researchers involved independently collected, analyzed, and interpreted the results from this study and have no financial interests concerning the outcome of this investigation.

Received: 14 September 2011 Accepted: 8 November 2011 Published: 8 November 2011 


\section{References}

1. Biolo G, Tipton KD, Klein S, Wolfe RR: An abundant supply of amino acids enhances the metabolic effect of exercise on muscle protein. Am J Physiol 1997, 273:E122-129.

2. Fujita S, Dreyer HC, Drummond MJ, Glynn EL, Cadenas JG, Yoshizawa F Volpi E, Rasmussen BB: Nutrient signalling in the regulation of human muscle protein synthesis. J Physiol 2007, 582:813-823.

3. Paddon-Jones D, Sheffield-Moore M, Zhang XJ, Volpi E, Wolf SE, Aarsland A, Ferrando AA, Wolfe RR: Amino acid ingestion improves muscle protein synthesis in the young and elderly. Am J Physiol Endocrinol Metab 2004, 286:E321-328.

4. Volpi E, Ferrando AA, Yeckel CW, Tipton KD, Wolfe RR: Exogenous amino acids stimulate net muscle protein synthesis in the elderly. $J$ Clin Invest 1998, 101:2000-2007

5. Volpi E, Kobayashi H, Sheffield-Moore M, Mittendorfer B, Wolfe RR: Essential amino acids are primarily responsible for the amino acid stimulation of muscle protein anabolism in healthy elderly adults. Am J Clin Nutr 2003 78:250-258.

6. Greenhaff $P L$, Karagounis LG, Peirce N, Simpson EJ, Hazell M, Layfield R, Wackerhage $H$, Smith K, Atherton P, Selby A, Rennie MJ: Disassociation between the effects of amino acids and insulin on signaling, ubiquitin ligases, and protein turnover in human muscle. Am J Physiol Endocrinol Metab 2008, 295:E595-604.

7. Coffey VG, Shield A, Canny BJ, Carey KA, Cameron-Smith D, Hawley JA: Interaction of contractile activity and training history on mRNA abundance in skeletal muscle from trained athletes. Am J Physiol Endocrinol Metab 2006, 290:E849-855.

8. Tang JE, Perco JG, Moore DR, Wilkinson SB, Phillips SM: Resistance training alters the response of fed state mixed muscle protein synthesis in young men. Am J Physiol Regul Integr Comp Physiol 2008, 294:R172-178.

9. Burd NA, Tang JE, Moore DR, Phillips SM: Exercise training and protein metabolism: influences of contraction, protein intake, and sex-based differences. J Appl Physiol 2009, 106:1692-1701.

10. Moore DR, Tang JE, Burd NA, Rerecich T, Tarnopolsky MA, Phillips SM: Differential stimulation of myofibrillar and sarcoplasmic protein synthesis with protein ingestion at rest and after resistance exercise. $J$ Physiol 2009, 587:897-904.

11. Wolfe RR: Effects of amino acid intake on anabolic processes. Can J Appl Physiol 2001, 26(Suppl):S220-227.

12. Phillips SM, Tipton KD, Aarsland A, Wolf SE, Wolfe RR: Mixed muscle protein synthesis and breakdown after resistance exercise in humans. Am J Physiol 1997, 273:E99-107.

13. Kimball SR, Jefferson LS: Control of translation initiation through integration of signals generated by hormones, nutrients and exercise. $J$ Biol Chem

14. Liu Z, Jahn LA, Wei L, Long W, Barrett EJ: Amino acids stimulate translation initiation and protein synthesis through an Akt-independent pathway in human skeletal muscle. J Clin Endocrinol Metab 2002, 87:5553-5558.

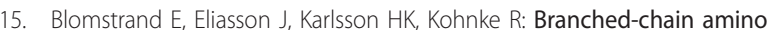
acids activate key enzymes in protein synthesis after physical exercise. $J$ Nutr 2006, 136:269S-273S.

16. Deldicque $L$, Theisen $D$, Francaux M: Regulation of mTOR by amino acids and resistance exercise in skeletal muscle. Eur J Appl Physiol 2005, 94:1-10.

17. Wang $X$, Proud CG: The mTOR pathway in the control of protein synthesis. Physiology (Bethesda) 2006, 21:362-369.

18. Moore DR, Atherton PJ, Rennie MJ, Tarnopolsky MA, Phillips SM: Resistance exercise enhances $\mathrm{mTOR}$ and MAPK signalling in human muscle over that seen at rest after bolus protein ingestion. Acta Physiol (Oxf) 2011, 201:365-72.

19. Greiwe JS, Kwon G, McDaniel ML, Semenkovich CF: Leucine and insulin activate p70 S6 kinase through different pathways in human skeletal muscle. Am J Physiol Endocrinol Metab 2001, 281:E466-471.

20. Liu Z, Wu Y, Nicklas EW, Jahn LA, Price WJ, Barrett EJ: Unlike insulin, amino acids stimulate p70S6K but not GSK-3 or glycogen synthase in human skeletal muscle. Am J Physiol Endocrinol Metab 2004, 286:E523-528.

21. Baar K, Esser K: Phosphorylation of p70(S6k) correlates with increased skeletal muscle mass following resistance exercise. Am J Physiol 1999, 276:C120-127.

22. Karlsson HK, Nilsson PA, Nilsson J, Chibalin AV, Zierath JR, Blomstrand E: Branched-chain amino acids increase p70S6k phosphorylation in human skeletal muscle after resistance exercise. Am J Physiol Endocrinol Metab 2004, 287:E1-7.

23. Um SH, D'Alessio D, Thomas G: Nutrient overload, insulin resistance, and ribosomal protein S6 kinase 1, S6K1. Cell Metab 2006, 3:393-402.

24. Tipton KD, Wolfe RR: Exercise, protein metabolism, and muscle growth. Int J Sport Nutr Exerc Metab 2001, 11:109-132.

25. Levenhagen DK, Gresham JD, Carlson MG, Maron DJ, Borel MJ, Flakoll PJ: Postexercise nutrient intake timing in humans is critical to recovery of leg glucose and protein homeostasis. Am J Physiol Endocrinol Metab 2001, 280:E982-993.

26. Cuthbertson D, Smith K, Babraj J, Leese G, Waddell T, Atherton P, Wackerhage $\mathrm{H}$, Taylor PM, Rennie MJ: Anabolic signaling deficits underlie amino acid resistance of wasting, aging muscle. FASEB J 2005, 19:422-424

27. Tang JE, Manolakos JJ, Kujbida GW, Lysecki PJ, Moore DR, Phillips SM: Minimal whey protein with carbohydrate stimulates muscle protein synthesis following resistance exercise in trained young men. Appl Physiol Nutr Metab 2007, 32:1132-1138.

28. Moore DR, Robinson MJ, Fry JL, Tang JE, Glover El, Wilkinson SB, Prior T, Tarnopolsky MA, Phillips SM: Ingested protein dose response of muscle and albumin protein synthesis after resistance exercise in young men. Am J Clin Nutr 2009, 89:161-168.

29. Shelmadine B, Cooke M, Buford T, Hudson G, Redd L, Leutholtz B, Willoughby DS: Effects of 28 days of resistance exercise and consuming a commercially available pre-workout supplement, NO-Shotgun(R), on body composition, muscle strength and mass, markers of satellite cell activation, and clinical safety markers in males. J Int Soc Sports Nutr 2009, 6:16.

30. Dreyer HC, Fujita S, Cadenas JG, Chinkes DL, Volpi E, Rasmussen BB: Resistance exercise increases AMPK activity and reduces 4E-BP1 phosphorylation and protein synthesis in human skeletal muscle. $J$ Physiol 2006, 576(Pt 2):613-24.

31. Rasmussen BB, Tipton KD, Miller SL, Wolf SE, Wolfe RR: An oral essential amino acid-carbohydrate supplement enhances muscle protein anabolism after resistance exercise. J Appl Physiol 2000, 88:386-92.

32. Borsheim E, Tipton KD, Wolf SE, Wolfe RR: Essential amino acids and muscle protein recovery from resistance exercise. Am J Physiol Endocrinol Metab 2002, 283:E648-57.

33. Spangenburg EE, Le Roith D, Ward CW, Bodine SC: A functional insulin-like growth factor receptor is not necessary for load-induced skeletal muscle hypertrophy. J Physiol 2008, 586:283-291.

34. Nader GA, Esser KA: Intracellular signaling specificity in skeletal muscle in response to different modes of exercise. J Appl Physiol 2001, 90:1936-1942.

35. Sakamoto K, Goodyear LJ: Invited review: intracellular signaling in contracting skeletal muscle. J Appl Physiol 2002, 93:369-383.

36. Dreyer HC, Drummond MJ, Pennings B, Fujita S, Glynn EL, Chinkes DL, Dhanani S, Volpi E, Rasmussen BB: Leucine-enriched essential amino acid and carbohydrate ingestion following resistance exercise enhances mTOR signaling and protein synthesis in human muscle. Am J Physiol Endocrinol Metab 2008, 294:E392-400.

37. Terzis G, Georgiadis G, Stratakos G, Vogiatzis I, Kavouras S, Manta P, Mascher $\mathrm{H}$, Blomstrand $\mathrm{E}$ : Resistance exercise-induced increase in muscle mass correlates with p70S6 kinase phosphorylation in human subjects. Eur J Appl Physiol 2008, 102:145-152.

38. Eliasson J, Elfegoun T, Nilsson J, Kohnke R, Ekblom B, Blomstrand E: Maximal lengthening contractions increase p70S6 kinase phosphorylation in human skeletal muscle in the absence of nutritional supply. Am J Physiol Endocrinol Metab 2006, 291:E1197-1205.

39. Deshmukh A, Coffey VG, Zhong Z, Chibalin AV, Hawley JA, Zierath JR: Exercise-induced phosphorylation of the novel Akt substrates AS160 and filamin A in human skeletal muscle. Diabetes 2006, 55:1776-1782.

40. Creer A, Gallagher P, Slivka D, Jemiolo B, Fink W, Trappe S: Influence of muscle glycogen availability on ERK1/2 and Akt signaling after resistance exercise in human skeletal muscle. J Appl Physiol 2005, 99:950-956.

41. Nave BT, Ouwens M, Withers DJ, Alessi DR, Shepherd PR: Mammalian target of rapamycin is a direct target for protein kinase B: identification of a convergence point for opposing effects of insulin and amino-acid deficiency on protein translation. Biochem J 1999, 344(Pt 2):427-431.

42. Koopman R, van Loon LJ: Aging, exercise, and muscle protein metabolism. J App/ Physiol 2009, 106:2040-2048. 
43. Rommel C, Bodine SC, Clarke BA, Rossman R, Nunez L, Stitt TN,

Yancopoulos GD, Glass DJ: Mediation of IGF-1-induced skeletal myotube hypertrophy by $\mathrm{PI}(3) \mathrm{K} / \mathrm{Akt} / \mathrm{mTOR}$ and $\mathrm{PI}(3) \mathrm{K} / \mathrm{Akt} / \mathrm{GSK} 3$ pathways. Nat Cell Biol 2001, 3:1009-1013.

44. Bush JA, Kimball SR, O'Connor PM, Suryawan A, Orellana RA, Nguyen HV, Jefferson LS, Davis TA: Translational control of protein synthesis in muscle and liver of growth hormone-treated pigs. Endocrinology 2003, 144:1273-1283.

45. Koistinen H, Koistinen R, Selenius L, Ylikorkala Q, Seppala M: Effect of marathon run on serum IGF-I and IGF-binding protein 1 and 3 levels. J Appl Physiol 1996, 80:760-764.

46. De Palo EF, Antonelli G, Gatti R, Chiappin S, Spinella P, Cappellin E: Effects of two different types of exercise on GH/IGF axis in athletes. Is the free/ total IGF-I ratio a new investigative approach? Clin Chim Acta 2008, 387:71-74.

47. Kanaley JA, Frystyk J, Moller N, Dall R, Chen JW, Nielsen SC, Christiansen JS, Jorgensen JO, Flyvbjerg A: The effect of submaximal exercise on immuno- and bioassayable IGF-I activity in patients with GH-deficiency and healthy subjects. Growth Horm IGF Res 2005, 15:283-290

48. Matheny R, Merritt E, Zannikos S, Farrar R, Adamo M: Serum IGF-Ideficiency does not prevent compensatory skeletal muscle hypertrophy in resistance exercise. Exp Biol Med (Maywood) 2009, 234:164-70.

49. Tang JE, Moore DR, Kujbida GW, Tarnopolsky MA, Phillips SM: Ingestion of whey hydrolysate, casein, or soy protein isolate: effects on mixed muscle protein synthesis at rest and following resistance exercise in young men. J Appl Physiol 2009, 107:987-92.

50. Nave BT, Ouwens M, Withers DJ, Alessi DR, Shepherd PR: Mammalian target of rapamycin is a direct target for protein kinase B: identification of a convergence point for opposing effects of insulin and amino-acid deficiency on protein translation. Biochem J 1999, 344(Pt 2):427-431.

51. Tipton KD, Rasmussen BB, Miller SL, Wolf SE, Owens-Stovall SK, Petrini BE, Wolfe RR: Timing of amino acid-carbohydrate ingestion alters anabolic response of muscle to resistance exercise. Am J Physiol Endocrinol Metab 2001, 281:E197-206.

doi:10.1186/1550-2783-8-18

Cite this article as: Cooke et al:: Ingestion of 10 grams of whey protein prior to a single bout of resistance exercise does not augment Akt/ mTOR pathway signaling compared to carbohydrate. Journal of the International Society of Sports Nutrition 2011 8:18.

\section{Submit your next manuscript to BioMed Central and take full advantage of:}

- Convenient online submission

- Thorough peer review

- No space constraints or color figure charges

- Immediate publication on acceptance

- Inclusion in PubMed, CAS, Scopus and Google Scholar

- Research which is freely available for redistribution

Submit your manuscript at www.biomedcentral.com/submit
Biomed Central 